\title{
To Study the Level of Culture Based Self Esteem among Students of Saveetha Dental College \& Hospital
}

\author{
Miss. Amanthi Ganapathi ${ }^{1 *}$, Dr K Karpagam ${ }^{2}$
}

\section{ABSTRACT}

Aim: To measure the level of self esteem among the students of saveetha dental college. Objective: To measure the level of self esteem of an individual's by inventory. Background: Self-esteem can apply specifically to particular dimension (for example: "I believe I am a good writer and feel happy about that") or a global extent (for example, "I believe sociology and psychology, self esteem reflects a person's overall subjective emotional evaluation of his or her own worth. In psychological literature the concept of self viewed in two ways. One in what is called the self as object. It refers to our capacity to stand outside of ourselves and to evaluate our attitude, feelings and behavior from a more or less detached point of view. Interest in the self humanity. It includes an active group of processes like thinking, remembering, perceiving, performing etc. Reason: This study is conducted to improve our aspiration towards self esteem and self worth which are considered to be the cornerstone of personality that influences the behavior of every individuals.

Keywords: Self esteem, Psychology, Behavior.

For the past hundred years, psychology has mostly assumed that individuals base their selfesteem on the fulfillment of the values they personally perceive as being most important. Seen in this light, self-esteem seems to be a mainly collaborative, as opposed to individual, undertaking. The system for building self-esteem is an important channel through which individuals internalize their culture's values at an implicit level, even if they claim not to subscribe to these values. These processes can encourage people to act according to the expectations of the society they live in, thus helping maintain social solidarity. Culture shapes various aspect of self: how people view the self, and what they strive to be or when they feel good or bad about themselves.

The self esteem is the cornerstone of personality that influences every behavior of a person. The person with high self esteem is eager and excite by new challenges. The individual is afraid to face choices, decisions, judgement and actions. On the other hand the person with low self

\footnotetext{
${ }^{1}$ Department Of Anatomy, Saveetha Dental College, Chennai, India

${ }^{2}$ BDS., M.Sc, PGDGC, Senior Lecturer, Department Of Anatomy, Saveetha Dental College, Chennai, India *Responding Author (c) 2016 I A Ganapathi, K Karpagam; licensee IJIP. This is an Open Access Research distributed under the terms of the Creative Commons Attribution License (http://creativecommons.org/licenses/by/2.0), which permits unrestricted use, distribution, and reproduction in any Medium, provided the original work is properly cited.
} 
esteem is often over whelmed anxiety and Lear. Such people retreat from the challenges of life and tend to bury oneself in the safety of familiar routine and undermining choices. This study will explain the culture in influencing self esteem.

\section{METHODS AND MATERIALS}

A survey based questionnaire was used to evaluate the culture based self esteem of individuals. A total of 52 people individuals pursuing I BDS from Saveetha Dental College \& Hospitals were selected. They were made to sit comfortably and were given the questionnaire to fill .The result were collected and tabulated.

\section{RESULTS}

TAB 1:-Tabulation showing self esteem with highest, lowest and average

\begin{tabular}{|l|c|c|c|}
\hline & HIGHEST & LOWEST & AVERAGE \\
\cline { 2 - 4 } HIGH SELF ESTEEM & 36 & 26 & 30.4 \\
\hline $\begin{array}{l}\text { MODERATE SELF } \\
\text { ESTEEM }\end{array}$ & 25 & 15 & 20.2 \\
\hline LOW SELF ESTEEM & 12 & 6 & 10 \\
\hline
\end{tabular}

Fig:-1 Bar Graph Representing Level Of Self Esteem

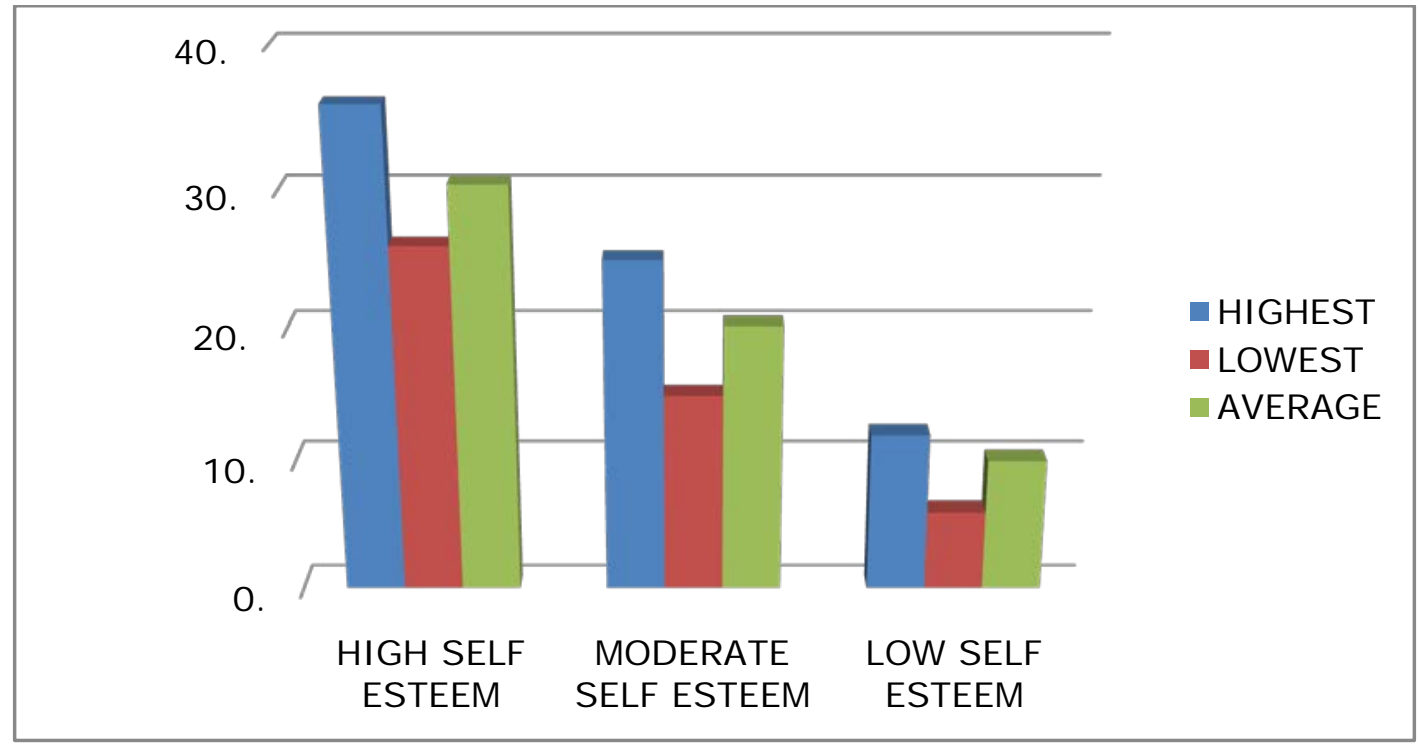


To Study the Level of Culture Based Self Esteem among Students of Saveetha

Dental College \& Hospital

Tab:-2 Tabulation Showing Number Of People With Their Of Self Esteem

\begin{tabular}{|l|l|}
\hline SELF ESTEEM & NUMBER OF PEOPLE \\
\hline PEOPLE WITH HIGH SELF ESTEEM & 26 \\
\hline PEOPLE WITH MODERATE SELF ESTEEM & 18 \\
\hline PEOPLE WITH LOW SELF ESTEEM & 8 \\
\hline
\end{tabular}

Fig:-2 Pie Chart Representing Number Of People With Their Self Esteem.

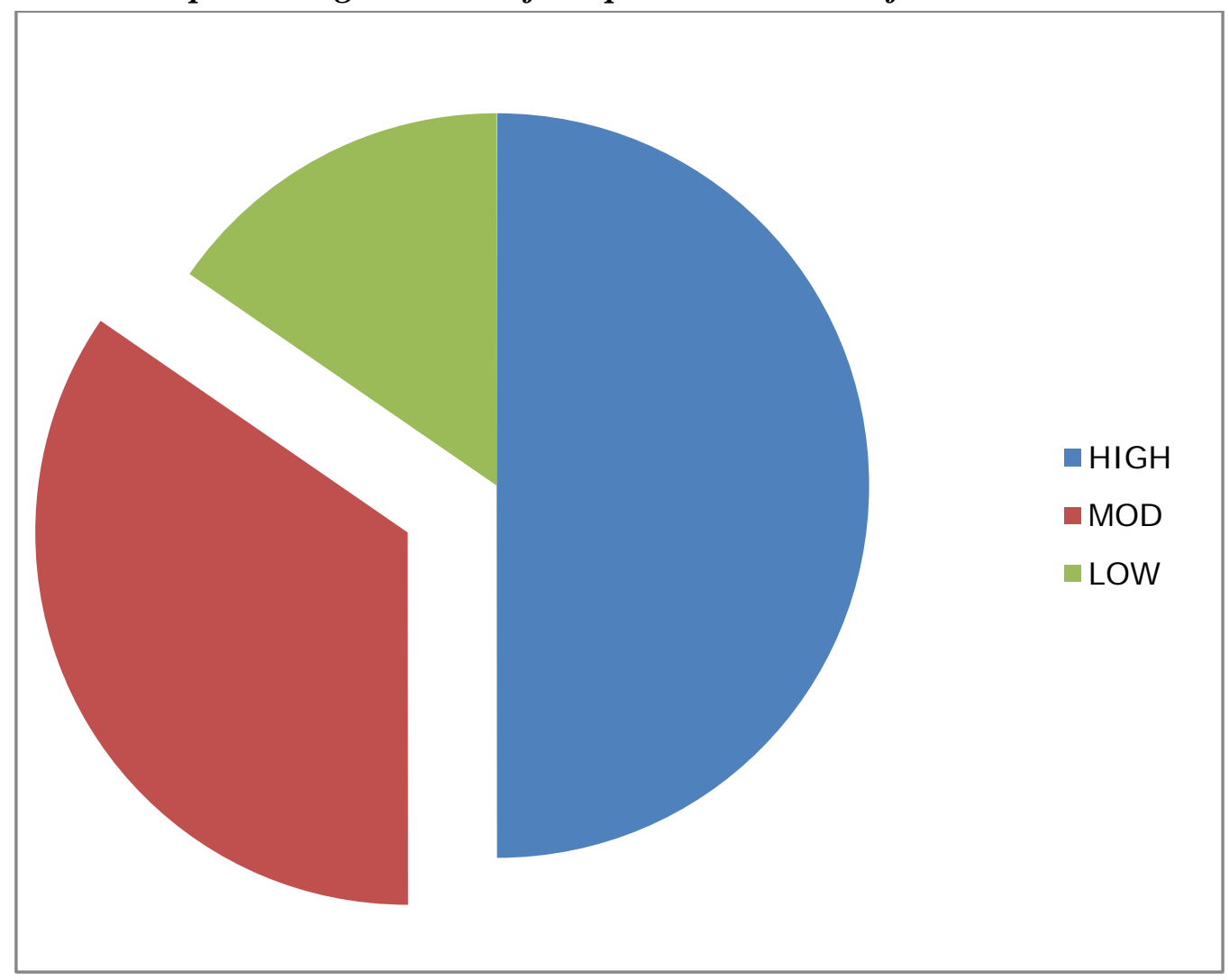

DISCUSSION

A survey based questionnaire was used to evaluate the culture based self esteem of individuals. A total of 52 people individuals pursuing I BDS from Saveetha Dental College \& Hospitals were selected. They were made to sit comfortably and were given the questionnaire to fill. Mark allotment for each question was given and evaluated and they were divided into three categories of self esteem with obtained range of marks. They were classified into high self esteem ,moderate self esteem and low self esteem group of people, and their average ,highest and lowest values for 52 people was evaluated( shown in tab:-1.)people with high self esteem who had highest value of 36,lowest value of 26 and average was found to be 30.4.people with moderate self esteem had highest value of 25, lowest value of 15 and average value is 20.2.People

(c) The International Journal of Indian Psychology, ISSN 2348-5396 (e)| ISSN: 2349-3429 (p) | 86 


\section{To Study the Level of Culture Based Self Esteem among Students of Saveetha Dental College \& Hospital}

with low self esteem had highest value of 12,lowest value of 6 and the obtained average value is 10.this was tabulated and the results are presented in the form of bar graph (fig:1).Then the total number of people who fall under the types of self esteem were calculated and their number was tabulated (tab:-2).in this people with high level of self esteem was found to be 26 in number, people with moderate self esteem were 18 in number and people with low self esteem was found to be 8 in number. These results were tabulated and presented with the help of a pie chart (fig:2). These findings suggest that the system for building self-esteem is an important channel through which individuals internalize their cultural values at an implicit level. These subtle processes can encourage people to act according to the expectations of the society they live in, thus helping maintain social solidarity. But, it is important for an individual to maintain moderate self esteem. So, that they can always be in a balanced state and take decisions properly and work according to their plans. People who have high self esteem become extroverts. People who have low self esteem become introverts. So, it is immensely important to change the high self esteem people and low self esteem people to moderate self esteem ones.

\section{CONCLUSION}

Self esteem has indeed become the identity of any individual and evaluating it is an important criteria before counselling is initiated. There are so much of factors like attitude, personality, family environment, per relationships, society which determines the self esteem. This study can help to create an awareness among one's self as well as among counsellors about the value of individual's self esteem. Highest and lowest levels, both will land up in stress related psychological issues, whereas, people with moderate self esteem tend to take proper decision and work accordingly. So, it is important to give counseling to people who have high self esteem and low self esteem to become moderate self esteem. So, that it will enhance their lifestyle.

\section{REFERENCES}

Brown, J. D. (2003). The self-enhancement motive in collectivistic cultures: The rumors of my death have been greatly exaggerated. Journal of Cross-Cultural Psychology, 34,603-605

Cultural bases for Self-Evaluation: Seeing Oneself Positively in Different Cultural Context” lead author Dr. Maja Becker, published in Personality and Social Psychology Bulletin, doi: 10.1177/0146167214522836

Roasenberg, M, \& Peralin, L. (1978).Social class and self esteem among children and adults. American journal of sociology,84,53-57.

Yik, M. S. M., Bond, M., \& Paulhus. D. (1998). Do Chinese self enhance or self efface? its a matter of domain. personality and social psychology Bulletin.24,399-406

How to cite this article: A Ganapathi, K Karpagam (2016), To Study the Level of Culture Based Self Esteem among Students of Saveetha Dental College \& Hospital, International Journal of Indian Psychology, Volume 3, Issue 3, No. 9, DIP: 18.01.161/20160303, ISBN: 978-1-36513820-1 